\title{
Experiences and Opinions of Contracted Teachers on Contractual Teaching Practice
}

\author{
Ali Kiş ${ }^{1}$, Perihan Altay ${ }^{2}$ \\ ${ }^{1}$ Assoc.Prof. Dr. Inonu University, Faculty of Education, Malatya-Turkey \\ ${ }^{2}$ Teacher at Mone, Şanliurfa-Turkey
}

\begin{abstract}
In this study, it is aimed to reveal the experiences and opinions of the contracted teachers working in the public schools in Hilvan district of Şanllurfa, which is one of the biggest cities of southeast Anatolia. The impact of the practice on teachers and on the educational environment will be revealed through the experiences of contracted teachers. In order to realize this aim, phenomenological design will be used. While collecting the data of the study, semi-structured interview form was prepared by taking the opinions of the experts in the field in line with the purpose of the study. The population of the study will be composed of contract teachers working in Hilvan district of Şanlıurfa in the academic year 2018-2019. The study group will constitute a certain number of teachers from each level in the district center. Quota and easy accessibility method will be used to determine the study group. While collecting the data of the study, in accordance with the aim of the study, twelve questions were prepared for the semi-structured interview form. Content analysis will be made to open-ended questions directed to contracted teachers. Since data collection process continues, the findings of the paper will be ready before the submission of full text to the conference. The results will consist of qualitative descriptive statistics and content analysis statistics, presented with tables and graphs. As expected outcome, there may be some social problems due to different culture and various contract conditions may force newly appointed teachers. Results of the research could indicate new insights to the educational administration literature. The results will be presented and discussed in detail in the light of previous related findings.
\end{abstract}

Keywords: Contractual teaching practice, contracted teachers; şanlıurfa; qualitative study 